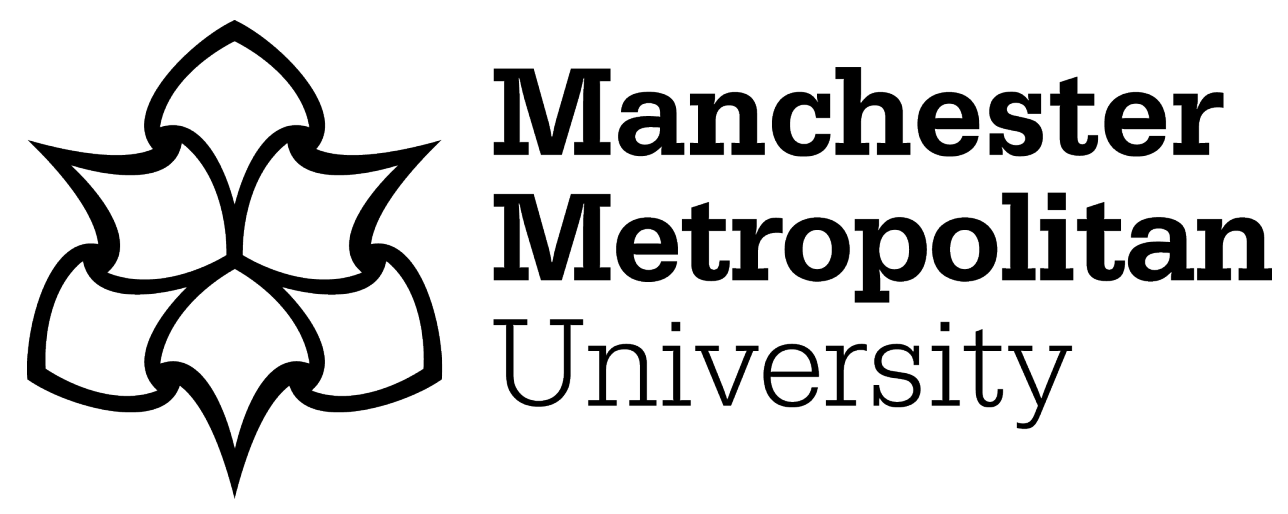

James, G ORCID logoORCID: https://orcid.org/0000-0001-7687-7392 (2016) Historical Frameworks and Sporting Research. The International Journal of the History of Sport, 33 (10). pp. 1169-1187. ISSN 0952-3367

Downloaded from: https://e-space.mmu.ac.uk/617447/

Version: Accepted Version

Publisher: Taylor \& Francis (Routledge)

DOI: https://doi.org/10.1080/09523367.2016.1221816

Please cite the published version 


\section{Historical Frameworks and Sporting Research}

\section{Introduction}

By 1985 , it was recognized that an historian's focus on sport history was of value and that research in our field had gained a 'new respectability' after the publication of several important studies. ${ }^{1}$ The field has since developed considerably with research focusing on a variety of sports, countries, regions and individuals, as well as consideration of sport's place within topics such as class, gender, race, fashion, media and so on. ${ }^{2}$ Leading academics working in our field have urged us to focus on writing good history, without worrying whether sport history is any more or less valuable than other sub-disciplines. ${ }^{3}$ Our field has developed significantly and, as a community, we have considered methodologies utilized in our research and have sought to develop ideas and encourage others to engage with methodological debates. ${ }^{4}$ Throughout the last three decades of sport history's own acceptance, or attempts at acceptance, into the mainstream of history academia, there have been challenges to our way of thinking. Researchers have begun to question some of sport's long established 'truths' and this has led to healthy debate and occasionally unhelpful criticism or even ridicule. ${ }^{5}$ Consider the origins of football debate that has been raging on for several years, particularly within the pages of this journal. ${ }^{6}$ It was not too long ago that historians and the general public felt they knew how association football was 'born', developed and propagated around the country. We believed there had been mob football, followed by a rediscovery of the game via the public schools whose pupils subsequently travelled around the country promoting the sport to communities. This explanation was chronicled extensively, but then historians researching sport at a local level started to question the earlier findings, leading to a wealth of valuable research in recent publications. ${ }^{7}$ However, rather than establishing a common theme, this research has led to competing theories with some historians believing in the 'orthodox' position, keeping faith with the traditional view, while 'revisionists' argued that the public schools were not as influential as traditionalists believed and that the lower-middleclasses were more relevant in the game's ultimate development. ${ }^{8}$ This has resulted in some researchers publishing academic articles listing every occurrence of the word football they have identified in online newspaper archives, with the intention that presenting a wealth of 
material in this manner will lead to the agreement that their preferred viewpoint is the right one. Of course, researchers on all sides of the debate could apply similar logic and, in all probability, discover material that suggests their version of the game's development is unequivocally the right one. Rather than regurgitate a particular view or present a wealth of material highlighting when the word 'football' appeared in digitized archives within this article, the decision has been taken to consider how the various versions of the game's roots could be brought together into an all-encompassing framework, detailing association football's evolution.

Much has been written about the game's origins, even if academics have differing views on what constitutes the birth of the game, with some focusing on the establishment of the Football Association as the pivotal moment, while others consider the influence of the Sheffield region. Some talk of the arrival of professionalism, while others consider the public schools and their adherence to their first rules. Some have talked of the footballing bans implemented at various points, suggesting that the sport had a role in daily life several hundred years before the sport's first known formal rules. If these varying interpretations are anything to go by, then it seems that we are no nearer to establishing the true development of the sport than we were a century ago. Back then, the early chroniclers of the game believed they had the answers, while today we know of the limitations they worked to. The debate between historians has at times appeared to become personal and often our academic papers appear to conflict and, in some cases, ridicule others for their mistakes or for conclusions we disagree with. ${ }^{9}$ There is a great need for academic rigour, of course, and we should challenge each other's findings, but when we are arguing over minor mentions of the word football and what they mean then this can be damaging. It could lead to fellow academics looking to those engaged in sport history as unprofessional with, perhaps, a return to the days when the social history of sport was looked upon as 'just another discrete historical ghetto where fans with typewriters practice their esoteric craft with little contact with the historical mainstream'. ${ }^{10}$ Discussion is healthy but the way the origins of football debate has been developing could be looked upon critically by fellow historians and, indeed, the wider public. At a time when academia needs to engage more than ever with the public, it is vital we also engage with each other and find ways to co-operate rather than criticize. We have powerful stories of social change to highlight and to inform the wider public, and the story of football's development 
can be utilized to establish good audiences for academia and prove the worth of our work and discipline.

This paper proposes the adoption of a framework based on the work of Fernand Braudel, and comprises of five sections with the first outlining Braudel's work; the second considers how Braudel's framework could be adapted to prove of value to sport history, the third section considers analysis of data, the fourth provides examples, and the fifth suggests how the proposed framework could then be applied. The paper concludes by suggesting that historians interested in soccer's early history work together, within the framework to develop a more detailed and all-encompassing early history of the sport. This framework will not claim that either the orthodox or revisionist view is accurate, instead it will determine how best to work those debates into an all-encompassing approach while searching for detailed evidence on what was actually occurring at local levels.

\section{Braudel's Concept}

To consider the framework being suggested it is important to consider the research of French historian Fernand Braudel. Braudel was not a sports historian but, as with most football historians today, he actively researched archives to search for material that may help provide new ways of considering history's dilemmas. In 1958 his research led to the publication of the Longue durée, ${ }^{11}$ where he argued that historians should consider three categories of social time - the Longue durée, Moyenne durée and Courte durée. Although these are not direct translations, it is fair to suggest that these three categories can be understood as the longterm, cyclical history and the history of events. ${ }^{12}$ It should be stressed however that cyclical history does not mean that this is a repetitive process, rather that this definition refers to the fact that activities at that level are cycles within a larger timeframe. Each definition is explored further later, but for the purpose of this section it is important to consider these periods at a high level with the Longue durée itself an embracing concept, providing the unifying element of human history. ${ }^{13}$ Braudel aimed to show that the historian's focus solely on event led history was flawed and that only by considering the long-term, and indeed the cyclical, or middle level, could we hope to establish a true understanding of the manner in which a society was established. He argued that over the long-term our collective behaviour is 
established alongside our enduring societal structures, while the cyclical level includes periods of major change. Some of these cycles may last for several decades or even centuries, while others last a few years, but each one adds to the overall progression. He believed that his views were marginalized by 'old-fashioned historians who emphasized political events and personalities' ${ }^{14}$ and, ironically, short-term history has again dominated in recent decades. ${ }^{15}$ Braudel's three time periods can be explained further:

\section{Longue Durée}

The Longue durée is typically perceived as a period of hundreds, if not thousands, of years. Usually considered to be boundless time ${ }^{16}$ or the full history of something, such as a nation or an organisation, and in Braudel's own work he published, for example, on geographical regions such as the Mediterranean. ${ }^{17}$ He believed that change is possible through human action overcoming the limits of the structures around them, including geographical and mental constraints. ${ }^{18}$ Braudel claimed that, for historians, the Longue durée is a structure that "travels through vast tracts of time without changing; if it deteriorates during the long journey, it simply restores itself as it goes along and regains its health, and in the final analysis its characteristics alter only very slowly. ${ }^{19}$

He believed this approach allowed historians a framework for them to observe and evaluate historical events and contextualize them within longer time frames.

\section{Moyenne Durée}

This level of time can be considered a period of development within the longer timeframe, and is often seen as measured in decades or potentially a century or more. ${ }^{20}$ It is a period where it is possible to discern a trend or a particular cycle, such as the Industrial Revolution. It contains a series of events that, when considered as a whole, demonstrate societal change. Dramatic fluctuations or attention grabbing events can be better interpreted within these cycles, with the trend becoming apparent the more we understand the individual events and the circumstances that surround them. ${ }^{21}$ Each cycle has its own causal explanations for how that cycle developed and these can include environmental conditions, for example the 
opportunity to use a field for sport; legislation, such as the banning of football activity; employment needs, such as longer working hours in a growing industrial city; or a multitude of other factors.

\section{Courte Durée}

Often understood to be a period of hours, days, weeks or maybe a year or so, this period is simply the time of an event or episode. In footballing parlance that could be an incident within a game, the match itself, or even a particular season. The history of events was not an area Braudel often focused on, preferring instead to consider the medium and long-term, ${ }^{22}$ and this was often perceived as a weakness of Longue durée theorists. Much of the criticism of Braudel's work focused on his perceived lack of interest in events and the limited volume of research into them by students of his and the Annales school. ${ }^{23}$ Braudel has documented his belief that events were the dust of time, ${ }^{24}$ with many events selected either retrospectively, once a pattern is known, or by those who have something to gain from highlighting an event at the expense of another. A criticism that could be levelled at some involved with the origins of football debate or at some of the early chroniclers of football. Wallerstein questioned the validity of historians utilising an event that occurred in one year, but was not reported until later years as he questioned whether this was truthful and whether it was any more significant than an event that was never chronicled. ${ }^{25}$ In the origins debate significance has been placed on villagers signing up to a football club in 1871 based on a booklet written some 38 years after the event was alleged to have taken place, written by a man with a vested interest. ${ }^{26}$ It seems plausible that Braudel and Wallerstein would have taken issue with judgements made on that individual event, especially as others claim that particular club's formation as occurring the following year. ${ }^{27}$ Braudel would have looked for the event's significance within the overall pattern. ${ }^{28}$

\section{Proposed Framework for Association Football}

Although the Longue durée encompasses the full history of a subject, ${ }^{29}$ it is worth considering how the framework is relevant to football. The full history of the sport could be told using an adapted version of Braudel's framework, with this section detailing how this could be applied. 
Accepting the Longue durée as the full history of football is fine, however to ensure the approach can be utilized to improve our analysis of soccer and development of our research it is important that clarity of the method and process is documented. In this section an adapted version of Braudel's concept is proposed, one which provides clarity and will benefit the work of academic historians working in the field of sport history. It is suggested that three separate levels of time do exist within sport history and, whereas many traditional sports historians may suggest that Braudel's concept is too vague, these can help to describe sport's development through critical analysis of archival sources. The following sections explain the three adapted levels of time.

\section{Full Time}

No game is complete until the final whistle is blown, and it is only then that points are allocated and winners can celebrate as they have a complete understanding of the game's life. Contestants, spectators and the game's chroniclers have experienced the full length of the contest and analysis can be made of the full time of the match, its twists and turns, teams' periods of dominance, possession, goals scored, corners taken, injuries suffered and so on. Each game has phases of play and specific incidents that shape its direction. As we all understand the concept of a game's full duration, it seems sensible to consider the entire history of soccer as one of 'Full Time' where every moment leads to its development. The sport continues to grow and develop which means that football has not yet reached its final whistle, but it is safe to assume that, as with sports media outlets, we can assess what we have experienced so far and reach conclusions on the developments along the way.

For the purpose of this paper, Full Time is the term utilized for the full duration of the sport, including the period before the first rules were formulated. On its own, this macro history level is important but it is only when it is combined with more detailed time frames at lower levels that we can start to seriously consider the complete picture. At full time in an ordinary game, scores are known, but only analysis within that game will show how that score was achieved, and the same is true for the Full Time history of football. Full Time allows us to contextualize events and their significance over the life of the sport and, of course, this approach could apply to sports clubs, competitions and so on. 


\section{Transformational Level}

This level is characterized by periods where the sport has developed or been transformed in some way. As Braudel suggests the way these middle level time periods, the cycles, are organized provides the structure. They provide the 'coherent and fairly fixed series of relationships between realities and social masses'. ${ }^{30}$ Those cycles, with their influences, outputs and inputs, demonstrate the general tendencies of sporting activity over time without being obscured by the attention-grabbing individual events. An individual game may be significant, but in terms of football's history it is the general pattern demonstrated within cycles that proves whether the individual game is part of a wider development or simply a one-off based on local influences. Our role as historians is to question why did the sport develop in the manner it did during this period and how did it change? What were the agents? We must identify the inputs, outputs, actions and consequences of each transformational period. We must also recognize that we may identify transformational periods that vary in significance on the Full Time development of the sport. Some transformational periods may only have significance on a local basis, like the establishment and life of a soccer club in Manchester in $1863,{ }^{31}$ but ultimately may have little bearing on the national development of the sport. In an ideal world we would create a Full Time history of soccer for every town, city, region, nation and internationally, but until we do so, we should construct a national picture based on what has already been researched and the regions academics are currently focusing on.

The aim of this level is to determine links and comparisons with individual episodes acting as rungs in a ladder moving the development of the sport onwards.

\section{Episodal Level}

Event led history is often perceived as important to sports historians where we can, and do, fixate on specific games, goals, trophy successes and so on. In the debate on the origins of football, some researchers have focused on finding events to add to their argument. 
However, it is important to remember that events on their own are not the 'story' and it may be that data, particularly that unearthed during an online search of a digitized newspaper, is abused if it is considered in isolation. ${ }^{32}$ The role of the historian as a challenging, interpretive analyst of all that is uncovered remains central to our work and, with so much data available via digitized material, it is important we ensure we consider all angles. To interpret sport's development it is important to look underneath, on top and alongside events to search for those events' true significance, and we must not abuse or misuse the record of the past. ${ }^{33}$ Successful historians analyse the study of events against the other two time periods to aid understanding of the deeper-running trend. ${ }^{34}$ It has been suggested that those focusing wholly on data gathering seem unable to appreciate this, ${ }^{35}$ and it is true that some historians can be prone to focus on individual episodes without performing true critical analysis of intellectual substance. Moving to a Full Time framework does not mean we reduce our efforts to investigate and analyse in detail, instead our role is to identify, measure and interpret the significance of individual events and interactions. We must seek out those events, connections, interactions that are hidden, and we must rescue from oblivion those whose voices and stories have not been heard. ${ }^{36}$ We need to consider if an event is relevant to a wider theme; a Eureka moment; or an inconsequential occurrence, giving careful consideration when we are questioning the significance of data and participating in a debate, such as the origins of football, where our academic community is divided by competing mythologies and disagreements over relevant context. ${ }^{37}$

It was suggested that Braudel's work lacked investigation of the effects of individual action on the creation of structures, ${ }^{38}$ and this is where the approach proposed in this paper develops his concept further, strengthening and appropriately recording the role of the event in sport's Full Time history. It is the investigation of the events at the Episodal Level that adds to transformational cycles at the next level. We need to interrogate these episodes to understand if and how they progress the sport, or play a part in a transformational cycle. Braudel believed the past presented a series of paradoxes for us to attempt to resolve with one such paradox being the inherent difficulties of recording and integrating immediate, short-term human experiences of the moment with the long range developments, ${ }^{39}$ but this is possible within a Longue durée framework, certainly within sport. Consider recent research into Manchester's earliest known club, Hulme Athenaeum, ${ }^{40}$ and the suggestion made that 
the club is not significant as it struggled for opponents and did not progress beyond 18631872. ${ }^{41}$ Looking at purely the individual events for that club could indeed suggest little significance, however, that view completely misses the point that a community was developed via that club which, over thirty years later, saw at least one founding member of that earliest known Mancunian club, still playing a leading role in developing and promoting regional football. ${ }^{42}$ His club may have died, but he and some of his colleagues remained leading footballing figures in the region for the rest of their lives. The interactions of both the individual and the team tell us a great deal about how football in Manchester developed and it is that level of detail, analysis and interpretation required in all regions that this paper hopes to promote via the proposed framework. Events at the Episodal Level are as important as the wider analysis because, without these the detail is lacking, but it is vital sports historians have a critical reading of the information discovered. This reading, by experts in their subject areas or regions, is what takes the individual moment and establishes its significance within a wider, transformational cycle, and interactions can become clear by studying these episodes. These webs of social activity help us to consider their influence on the wider history of the sport, assisting in our determination of transformational cycles. Social interactions lead to invention and innovation and help progress the Longue durée of a topic. ${ }^{43}$

\section{Analysis}

To ensure the framework fits with our research needs, it is worth considering the process of analysis. Analysis of detail is important to understanding the Full Time of an activity, and in recent decades it has been claimed that the focus of 'babyboomer historians' has been on the micro-history of subjects such as class and race, while some long range historians have ignored detail in favour of the overall trend. ${ }^{44}$ This may be appropriate for their studies, however, to understand long range history it is important to investigate, analyse and interpret the detail as well as the general theme. The knowledge of individual events shapes and informs each transformational cycle and they in turn help the Full Time of an activity to develop. It is the understanding of how episodes interrelate that shapes a cycle and it is these complex relationships that we need to understand if we are to map the full history of a sport or, indeed, its origins. Each episode on its own may not be significant, even if some historians view a solitary reference to the word 'football' as being important, but it is the identification 
of whether these single events are turning-points, or merely an isolated episode that is important. Some historians researching football's origins have focused on online newspaper mentions in digitized archives which, as Johnes and Nicholson have highlighted, can lead to misinterpretation and a lack of knowledge of the wider context of the piece. ${ }^{45}$ The availability of digital archives has allowed historians to unearth a plethora of episodes or events and for those of us who cut our research teeth by poring over microfilmed newspapers in the 1980s, the opportunities are endless. However, it should be remembered that these archives are indicative of activity rather than conclusive as they provide evidence that needs to be analysed and questioned, but not the answer. We must remain vigilant and recognize that some footballing activity was never reported; some was reported but not in sufficient detail; some reports were lost; some records withheld and so on. There is also the issue of how newspapers were selected to be digitized. We should question what has been made available, why, by whom, the funding and so on, as this may provide answers to other questions about how we perceive history, news and national significance. The British Library's digitisation project, for example, paid little attention to sporting newspapers until recently, while some universities have sought to digitize sporting collections which will aid their own priority projects. ${ }^{46}$

As with any historical research, critical analysis by experts in their subject areas is required. We need to search for the evidence of what occurred and we need to interpret it by placing it into context. There should be nothing new about this process as all academic historians have been trained to do this through their own educational systems and research experience. Take a simple report such as one which talks of twelve or thirteen people 'playing of football' on the frozen Serpentine in Hyde Park, reported in $1840 .{ }^{47}$ The report focuses on the rescue of some of the people and the death of one of the party but, from a sports context, some historians could utilize that report to suggest that football was being played in all conditions in central London. That would be a conclusion that seems extreme but that is exactly what we appear to be getting at times in the origins of soccer debate. What we should actually be doing is straightforward investigative work and we need to ask why were they playing on ice? Where did they get the ball? Was it sold locally, and if so how many balls were sold each week and what size and shape were they? Was it significant that the number of players was twelve or thirteen? How did they balance the teams? Did they have teams or 
was it a general kickabout? What were their aims? Why play on the ice in the first place? The questioning, of course, must continue until we uncover enough answers to establish the event's true significance, and it may be that we simply cannot find enough answers to make a valuable assumption about the activity being performed. The individual episodes have to be considered for how they relate to each other - the themes, processes and significance. It is not necessary to make every individual episode fit within the theme of a transformational cycle, but it is vital to consider whether the episode is part of a cycle or is it merely a one-off event, an outlier, or of no significance whatsoever.

Once we have identified enough episodes to see a pattern emerge, then we must consider whether that pattern is strong enough to be perceived as a transformational cycle. Within a transformational cycle, we must see a clear development or change from the previous cycle. As an example, consider the move towards professionalism in English soccer during the 1880s. Our research of that period needs to identify the key episodes that led to the sport allowing professionalism across the country; the debates; the threatened breakaway by northern clubs; the meetings held; and every instance of player payment we can find. We will then need to analyse these episodes and search for their significance, and will need to consider what the inputs into this transformational cycle and the outputs are, such as the establishment of competitions for professionals and amateurs; wage constraints; increased movement between clubs; impact on admission charges and so on. That transformational cycle can then be appropriately placed in the Full Time history of the sport. If researchers can focus on their specialist areas and identify the events, circumstances and cycles that matter to them, documenting how events form cycles and how those cycles transform into the following cycle, then we will produce an all-encompassing history of football. Of course, this approach requires academics to collaborate and for some to act as stewards, signposting the way around the three time levels and helping others to formulate their own research questions, mapping and cycles as they uncover the micro detail necessary to understand what was happening at a local level, alongside identification of transformational cycles, and within the Full Time of the sport. This approach will help to make the history of football's development comprehensible and based on fact, rigorously assessed with each episode identified for what it is, whether that be as part of a wider transformational period, or simply a one-off episode. We must review each other's work and look for 
similarities and agreements to inform the wider picture. Where we disagree we must consider why we hold the views we do and look for a means of bridging those disagreements. By focusing on commonality, we will be able to establish a historical truth, one that adds value and can be further researched and analysed. Co-operation is necessary, ${ }^{48}$ but alongside this we must communicate our findings positively and support each other in bringing our research to the wider public. Soccer matters to people and provides an opportunity for valid, genuine, thought-provoking history to be discussed by academics and non-academics alike. The proposed framework allows us to share ideas and encourages debate, it is not simply about re-introducing an old idea and making it fit with the modern world, as it allows us to question the significance of the smallest football reference, to search for sequences, to establish the transformational nature of cycles, and to create an all-encompassing history of the sport. We need to combine low-level detail, identified through indepth archival research and local knowledge, within a Full Time history, while identifying transformational cycles and all their associated inputs and outputs. This approach will allow historians to engage with each other and with the public in a manner that can only benefit our discipline. It gives us both the micro history that we have become accustomed to in recent decades and an understanding of how that detail has shaped our sport's development over centuries. It provides the best of both worlds - deep plundering of the archives with the critical analysis of what shapes society over the long-term. Searches of digitized records provide opportunity but they do not provide the answer on their own. Instead we need to immerse ourselves in the data and interpret it wisely, searching for patterns of activity, community development and progression. It is essential we provide informative answers to the questions of how football became established as a sport; how it developed and where it was played.

The Full Time history of football's development would include current events of course, and this is where weaknesses can occur because, while we are still experiencing and living the sport's development, we will find it difficult to analyse and identify transformational cycles developing at the moment, although the game's globalisation has already received some focus as part of a 'world system' ${ }^{49}$

\section{Examples}


To help explain the proposed framework further, the following examples have been provided of well known footballing moments to demonstrate how these events can be interpreted within a Full Time framework of soccer. The first is a modern example. In 2012, Sergio Agüero scored a goal in the dying seconds of the final game of the season to win the Premier League in 2012. The goal has been replayed frequently and is seen as 'the' story of the 2011-12 soccer season. Using this as an example of Full Time history, that goal was an event within the Episodal Level, important but not the full story. The Transformational Level could be said to be the 2011-12 season itself or, more appropriately when considering the significance of this level, it could be interpreted as a period characterized by overseas ownership of Premier League clubs. A period that for Agüero's club, Manchester City, started in 2007, but for the Premier League goes back further with, of course, Chelsea being perceived as one of the earliest clubs to benefit from the patronage of an overseas investor. As the Agüero example demonstrates, this framework provides a method to formulate questions about change. Here we question why was Agüero playing for Manchester City and, with the right questioning we trace back to the investment in the club by Sheikh Mansour and on to the overseas ownership of clubs. We do not simply state that Agüero's goal won the League, we analyse every aspect of that event and see that it is merely one episode within a more significant transformational cycle, where overseas ownership of Premier League clubs became prevalent.

Looking further back, there is the example of the First Division of the Football League being increased from 20 clubs to 22 in $1919 .{ }^{50}$ This move was agreed at a special meeting of the League and it has been suggested that this increase was to ensure London clubs remained in the top flight to prevent a breakaway of southern clubs. ${ }^{51}$ However, the special meeting of the League was merely one event within a much longer debate that stretched back to April 1915. Reports of the Football League discussions in 1919 show that the decision to increase the size of the First Division had come as a protective measure following a fixed game between Liverpool and Manchester United on Good Friday 1915. That game resulted in a dubious victory to Manchester United and, after investigation, it was proved that players from both clubs had agreed to fix the match as part of a betting scandal. The points accrued by United were enough to ensure that at the season's end the club would not be relegated, and that Chelsea would be, although the match fix was not proven to have been an attempt at saving United from relegation. The debates surrounding the fixed game rumbled on 
throughout the war and, when officials decided to increase the League, there were protests from other clubs including Everton who held the view that the League should not be increased and that Manchester United should be relegated as the guilty party. ${ }^{52}$ The significance of these comments are that a simple episode, such as the increase in membership of the Football League, is merely one event within a sequence of events at the Episodal Level and that, in this case, analysis of each League meeting and an interrogation of material, reveals a broader series of episodes. The increase in League is often shown from the perspective of the Arsenal promotion and Tottenham relegation, but had the Liverpool-United match fixing scandal never occurred then the prospect of saving Chelsea from the punishment of relegation may never have been discussed. The mood of those meetings was that Chelsea were hard done by, with little said about Tottenham's plight, but this often gets overlooked today as we consider the apparent injustice of Tottenham being relegated from a division that is about to be increased, for Arsenal. There is a significance to that, of course, and this adds to the need to research and document the Full Time history of football, with patterns identified at the Transformational Level and individual events at the Episodal Level. In the case of the League's expansion, that is clearly a Transformational cycle containing a series of episodes such as the Liverpool-United game and the various meetings along the way.

Another example concerns an event that has been raised by those with opposing views in the origins debate. This is a game of football advertised in Ashton-under-Lyne during the $1840 \mathrm{~s} .{ }^{53}$ This match may or may not have occurred, leading to differing interpretations from modern day historians with some suggesting that the advertisement means little, while others use it as evidence that a footballing culture was in existence. ${ }^{54}$ On its own the newspaper advert for the game can indeed be interpreted either way, but what it actually demonstrates is that our knowledge of the circumstances peculiar to that event is not yet sufficient enough to provide a definitive answer. What is needed is a full investigation into the environment around Ashton-under-Lyne at that time, along with analysis of the named individuals, groups and locations, to understand whether the pattern within that locality adds to evidence that can then be interpreted as part of a transformational period of activity. Research into the eight miles that surround Manchester has identified that the Ashton area had multiple teams in existence by the end of the 1870s, with other footballing activity reported between 1846 and the 1870s, and this suggests that the 1846 advertised game may 
well have been a key episode in the development of the sport locally, ${ }^{55}$ but further investigation is required.

At present, we cannot say whether the Ashton game is an outlier, statistical evidence of activity that was not part of an overall pattern, or whether it represents a much stronger community of activity than previously understood. The suggestion is that it followed, and was followed by, other evidence of footballing action in the Ashton locality, and if we could prove that subsequent footballing activity in the Ashton area involved some of the people mentioned in the advert, then clearly that is of more significance. This framework allows historians to question what an event or period actually meant to the long-term development and encourages historians to 'look underneath it and see it in terms of the long-term, asking was it epiphenomenal? Was it momentary? Was it a kind of flash? Or did it really make a difference $?^{\prime 56}$ This approach enables us to take a more considered approach when analysing an event's significance. One event, such as the formation of a football club, is only significant to the overall story if that club's establishment tells us something that influences our understanding at the Transformational Level and, indeed, within the Full Time history. This means that to truly understand the development of football we need to consider each level in turn and so, rather than this framework appearing to be a vague overarching explanation for football's development, it actually becomes a precise analysis of data and phenomena. In this proposed framework, the work of dedicated researchers is vital but instead of simply looking for events at the Episodal Level and, for example, considering whether they support the orthodox or revisionist viewpoints, researchers need to consider the three levels of time to improve our overall understanding.

\section{Suggested Research and the Transformational Level}

If we accept this framework and recognize that three separate time periods exist, then the logical way forward is to gain a global understanding of what occurred within each transformational cycle. We need to agree what those cycles are, research them and document the inputs, influences and outputs of each cycle. Identifying these cycles and producing a descriptive analysis of what occurred within each cycle, and of how each cycle 
transforms into another, will allow historians to produce a history of football that is all encompassing. ${ }^{57}$ One off events and games will be important in our research but not necessarily significant in the overall history of the sport. As the origins debate has demonstrated, recognising the specifics behind the formation of a cycle can be complex but it is an activity worth pursuing. . The first step would be for high-level analysis to be made breaking the Full Time history of the sport down into transformational cycles. This would allow historians to focus on their own specialities within a wider framework with the aim of filling in the gaps to make their research add real value to the determining of the key episodes within a transformational cycle. The need for indepth, local research is vital, but where this differs from what has been happening so far is that historians will work together focusing on micro-history to inform, via the suggested framework, the Full Time history of our sport. Combining micro-historical research with a macro-historical framework can prove the value of our work, provide real meaning to our conclusions and can bring consensus on what really matters. ${ }^{58}$

For the purposes of this proposal, it is essential to give an indication of the type of Transformational cycles that appear to exist. These should be debated, but they have been presented here to help progress the adoption of a Full Time framework for soccer. Analysis so far suggests eleven broad Transformational periods, ${ }^{59}$ including four periods focusing on what could be described as the origins of the game: Mob Football; Early Forms of Football; Establishment of Clubs and Competitions; and Professionalism. An analysis of Manchester's association football development up to 1919 is to be published utilising this Full Time framework, with research for that publication identifying appropriate transformational cycles for that region. ${ }^{60}$ Figure 1 provides a basic overview of the first six Manchester transformational cycles, as an indication of how the three levels co-exist. Although in depth research in Manchester has identified time periods, it would be unwise at this stage to place a timeframe alongside any of the national transformational periods, as detailed analysis is required. The significance being to search for the events of the game's past and consider how they link together to form a pattern of activity. By focusing in this way we can interpret how events have shaped the sport while also understanding the circumstances that enabled or prevented the sport's progression. The position at the start of each transformational cycle and at the end needs to be documented, as do the individual mentions of football within each 
cycle, some of which will progress the sport, some will have no impact whatsoever, and some will add a geographical perspective on where footballing activity was occurring. Outliers are of interest of course, but it is the cycle that aids our overall understanding. Once we have identifiable transformational periods we can then understand how these link together to form the game's history. Many factors, including environmental and political, have helped shape sport, and it is clear that all of these factors need to be considered alongside the simple events identified at the Episodal Level.

To develop this framework, we need more regional studies; agreement of transformational cycles (possibly with bespoke regional cycles); to map the full growth of the sport; and to agree on the inputs and outputs for each cycle. Instead of looking for differences, which many historians can be guilty of, we should pay more attention to similarities. ${ }^{61}$ We can take the regional research already performed and combine it all within the proposed framework to identify patterns, consistencies and trends, while also taking steps to encourage research into the areas where gaps exist. Causal explanations can be complex and often not easily identified but it should be apparent that for any sport to develop there needs to be a series of factors that come about perfectly to create a Goldilocks 'just right' opportunity. Understandably, some will consider that this framework is simply 'history', however the suggested framework is more about making sense of the Full Time history of the sport and its transformational phases, rather than focusing on the eureka moments. It is an embracing theory, and is a subtle change in the way we think, but it could have a significant impact on our understanding and interpretation of how the game developed. Historians have an important role to play in ensuring our findings are fact based, comprehensive and comprehendible, and it is vital we question our approaches and develop standards and frameworks that help us come to terms with the modern, digitized world of academia where information overload ${ }^{62}$ could make our community appear in conflict and disjointed with little of worth to add. We must not stand still or worse, retreat into our own particular comfort zone, while criticising those that disagree with us. We must embrace each other's work and join forces to create a comprehensive history, within a framework that makes sense of it all, while developing roles to provide critical assessment of how the data uncovered in the Episodal Level fits into a transformational cycle and, ultimately, into the Full Time of the sport. 
The author intends to organise a conference where historians genuinely interested in moving towards this Full Time framework can collaborate with the aim of establishing an allencompassing history. As part of this collaboration, the work of historians may vary, with some focusing on the detail and others providing critical consideration of how the data fits into the proposed levels of time, but all will help seek agreement on the development of the game. It is apparent that each period of substantial development has its own unique series of events and its own particular explanatory forces in a manner suggested by Bober when considering economic cycles. ${ }^{63}$ Economists and scientists recognize the concept of cycles, ${ }^{64}$ supporting the concept of the Transformational Level, although each cycle has its own experience, they are outgrowths of processes from the preceding cycle, ${ }^{65}$ which means that as we identify the inputs to a cycle, we will be able to recognize the constants in existence from the previous cycle. The development from mob football to public school and rule based football is hotly debated at present, what this framework will help to demonstrate is exactly what footballing activity continued across those two transformational periods, along with, hopefully, the details of communities that continued to participate and the individuals who promoted the sport's development. For sports historians, the Transformational Level with its periods of change provides the opportunity to identify continuities and shifts in sports development.

\section{Conclusion}

Historians are fully aware that extensive research is vital in understanding how our sports developed, but it is also clear that providing a framework within which gaps can be identified is also important. Guldi and Armitage have claimed that since the 1960s academia has encouraged students to focus on narrow time frames and on the local, ${ }^{66}$ and this appears to be true for the sport history community. We have tended to focus on regional histories and restrictive timeframes without much consideration of the Full Time history of our subject. We have perhaps fooled ourselves into thinking that our own limited time periods, and focus on local issues, will provide answers to the wider picture but in truth, by not properly positioning our research within a longer duration and wider framework, we have limited the possibility of reaching conclusions that genuinely answer our questions. Instead we have, particularly in the origins of football debate, provided multiple views of how the game developed, with some 
historians taking great delight in challenging those that have disagreed with their own perceptions. This has led to historians focusing on their own specialist area and their role in the debate, limiting their public engagement and readership in the process in a manner suggested by Guldi and Armitage. ${ }^{67}$ Historians need to engage with each other and, perhaps more importantly, with non-specialist readers if their work is to be of value, rather than exhibit a 'my research is better than yours' approach which has, at times, appeared to be the motive in some academic papers on the origins of football. This is unhealthy. This does not mean that historians working in a narrow field and timeframe have nothing to offer, or that their work is of less value, far from it. Detailed research of this nature is absolutely vital, but it has to be recognized that, in many cases, the material identified is at the Episodal Level of time, and that it requires considering at both the Transformational Level and within the sport's Full Time.

By collaborating on the propagation of a Full Time framework, as proposed earlier, will allow all of our regional and time restricted studies to be included within a wider analysis and will move the debate forward. The aim is to take the small detail to help create the bigger picture, and that is surely worth achieving? Cannadine believed that historians were producing increasing amounts of academic history that 'fewer and fewer people' were actually reading and, if the altmetrics and read figures for some papers on the origins of football are to be utilized as a barometer, his view appears to be true for most, but not all, football origins papers. ${ }^{68}$ By suggesting historians collaborate on the development of this framework, this paper concludes with the view that this over-arching approach will enable historians to combine both the orthodox and revisionist research identified to date to develop a robust historiography of the sport. Some sports historians, such as McDowell, have documented the need to identify the phases and themes in the historiography of sport, indeed McDowell has published a critical assessment of the research into Scottish football still required based around phases which is, in essence, the beginning of establishing a Full Time history of Scottish football. ${ }^{69}$ McDowell's approach has added value and, if we work together to utilize the proposed framework, we can provide an all-encompassing view of the history of football, based on the widest range of material and theorizing, providing a credible approximation of the topic's history. ${ }^{70}$ 
The discipline of sport history could be improved if we followed a framework, such as that proposed, and added proper context to it by interpreting episodes and archival records correctly, while explaining our findings together to as wide an audience as possible. Let us not spend our time arguing in academic journals and instead seek ways to understand why any differences exist. Johnes talked of the opportunity for historians to attract people to historical study, for universities to become embedded in their communities, and called for sports historians to recognize the need to engage more if our role is to prove valuable in the future, and his views should be considered. ${ }^{71}$ Other historians, such as McKibbin, ${ }^{72}$ have questioned the position of sport history and what developments we need to make, adding to the view that there remains some uncertainty of the direction of the field. The Full Time framework proposed here provides an opportunity for those researching football's formative years to demonstrate real value, leading to the establishment of a universal history of football which considers all of our findings, starting with the origins of football, and then disseminate it to our communities. A common approach will allow us to engage with a non-academic audience at varying levels to ensure we inform non-specialists about the Full Time history of our sport, transformational cycles, individual 'headline grabbing' episodes and our regional position within the sport's full narrative. Other areas of history have recognized that we must engage with the public by 'developing a longue-duree contextual background against which archival information, events and sources can be interpreted, ${ }^{73}$ and as Vamplew has stated, sport is no different from other areas of history. ${ }^{74}$ It is time for us to adopt a framework and processes that we can all work toward. We have the tools and the technological means to overcome many of the traditional objections to considering long-term history. ${ }^{75}$ This approach will produce a more critical, intensive and valuable synthesis of material and will ensure that each regional study adds to the whole, rather than appearing as a rival position.

Full Time history can be applied to any aspect of a sport's existence, and while this paper has focused on soccer origins it could equally apply to other sports, individual clubs, international competition and so on. The beauty of this framework is that it allows us to think both big and small, to consider the lowest level of detail, alongside the widest possible theme. There is a place for all to contribute their local, regional and specific research within the Full Time history of the sport, without our topics being confined or, as Sherratt commented, 'ghettoised'. ${ }^{76}$ Any aspect of sport can be researched within this framework by considering a 
series of successive developments, regionally, nationally and internationally, looking for the individual moments and understanding how they influence that particular developmental period. This may require a different approach within the supervision and education of students but, with the right amount of training, there is no reason why historians cannot approach the proposed framework with optimism, hope and ambition. McDowell asked whether there were historians who desired a different route for Scottish football's historiography, and this paper concludes with a similar question. ${ }^{77}$ Do we want to work together to produce an all-encompassing history of our sport, one which will help us engage with the general public, or do we want to demonstrate to the outside world our differences and squabbles?

The author is keen to hear from academics researching in this field with a desire to collaborate on defining the Full Time history of association football.

Caption for Figure 1:

Research into Manchester's Full Time history of association football has identified six transformational cycles, which chronicle the early development of the sport in the region. Each event and newspaper reference identified has been analysed at the Episodal Level to determine its significance, and to consider whether patterns of activity have emerged. Where a significant progression has been observed further analysis has determined how those events have influenced a transformational cycle. The events listed are merely to give an indication of the type of event considered within each cycle. This research has, for example, helped identify the significance of Hulme Athenaeum with its first secretary in 1863, John Nall, directly linked with the formative years of both Manchester City and United, and he continued to play a significant role in the development of regional soccer through to his death in 1897. 


\section{Notes}

${ }^{1}$ Karen J Winkler, 'A Lot More Than Trading Baseball Cards: Sport History Gains A New Respectability', Chronicle of Higher Education, 5 June 1985, 5-9.

${ }^{2}$ Reviewing the article titles in the latest issues of journals such as the Journal of Sport History, The International Journal of the History of Sport, and Soccer and Society demonstrates the breadth and variety of topics.

${ }^{3}$ Wray Vamplew, 'Sporting a Handicap: Mainstreaming Sports History', International Sports and Leisure History (Spleish), 'Future for Sports and Leisure History' Symposium, http://www.cheshire.mmu.ac.uk/sport-history/blogs.php (Accessed 10 August 2015).

${ }^{4}$ For example Samantha-Jayne Oldfield, 'Narrative Methods in Sport History Research: Biography, Collective Biography, and Prosopography' The International Journal of the History of Sport 32, no.15 (2016), 1855-1882; Duncan Stone, John Hughson and Rob Ellis (eds.), New Directions in Sport History (Abingdon: Routledge, 2015); and Mike Huggins, 'The Visual in Sport History: Approaches, Methodologies and Sources 32, no.15 (2015). ${ }^{5}$ Examples include Peter Swain, 'Early Football and the Emergence of Modern Soccer: A Reply to Tony Collins', The International Journal of the History of Sport DOI: 10.1080/09523367.2016.1173032 (2016); Graham Curry and Eric Dunning, Association Football: A Study in Figurational Sociology (Abingdon: Routledge, 2015), 155-174; RW Lewis, 'Innovation not Invention: A Reply to Peter Swain Regarding the Professionalization of Association Football in England and its Diffusion', Sport in History 30, no.3 (2010), 475488; Peter Swain, 'Cultural Continuity and Football in Nineteenth Century Lancashire,' Sport in History 28, no.4 (2008), 566-82; Adrian Harvey, 'Curate's Egg Pursued by Red Herrings: A Reply to Eric Dunning and Graham Curry', The International Journal of the History of Sport 21, no. 1 (2004), 127-31; and Adrian Harvey, 'The Curate's Egg Put Back Together: Comments on Eric Dunning's Response to an Epoch in the Annals of National Sport', The International Journal of the History of Sport 19, no. 4 (2002), 191-9.

${ }^{6}$ Articles include Tony Collins, 'Early Football and the Emergence of Modern Soccer, c.1840-1880', The International Journal of the History of Sport 32, no. 9 (2015), 1127-1142; 
Gary James, 'Manchester's Footballing Pioneers, 1863-1904: A Collective Biography', The International Journal of the History of Sport 32, no. 9 (2015), 1143-1159; Peter Swain and Adrian Harvey, 'On Bosworth Field or the Playing Fields of Eton and Rugby? Who Really Invented Modern Football?', The International Journal of the History of Sport 29, no. 10 (2012), 1425-45; Gavin Kitching, "“Old” Football and the "New" Codes: Some Thoughts on the Origins of "Football" Debate and Suggestions for Further Research', The International Journal of the History of Sport 28, no. 13 (2011), 1733-49; Robert Lewis, 'The Genesis of Professional Football: Bolton-Blackburn-Darwen, the Centre of Innovation, 1878-85', The International Journal of the History of Sport 14, no.1 (1997), 21-54.

${ }^{7}$ In addition to those mentioned elsewhere in this article, these include Curry and Dunning, Association Football; Gavin Kitching, 'The Origins of Football: History, Ideology and the Making of “The People's Game”, History Workshop Journal 79, no. 1 (2015), 127-153; Graham Curry and Eric Dunning, "The "Origins of Football Debate" and the Early Development of the Game in Nottinghamshire', Soccer and Society DOI: 10.1080/14660970.2015.1067801 (2015); Gary James and Dave Day, 'The Emergence of an Association Football Culture in Manchester, 1840-1884', Sport in History 34, no. 1 (2014), 49-74; Matthew L. McDowell, A Cultural History of Association Football in Scotland, 1865-1902 (Lampeter: Edwin Mellen Press, 2013); Swain, 'Cultural Continuity’; Thomas John Preston, 'The Origins and Development of Association Football in the Liverpool District, c.1879 until c.1915', PhD thesis, University of Central Lancashire, Preston, 2007; Neal Garnham, Association Football and Society in Pre-Partition Ireland (Belfast: Ulster Historical Foundation, 2004); Ian Nannestad, 'From Sabbath Breakers to Respectable Sportsmen: The Development of Football in Lincolnshire circa 1855 to circa 1881', MA thesis, De Montfort University, Leicester, 2003; Martin Johnes, Soccer and Society in South Wales, 1900-1939 (Cardiff: University of Wales Press, 2002); Adrian Harvey, 'An Epoch in the Annals of National Sport: Football in Sheffield and the Creation of Modern Soccer and Rugby', The International Journal of the History of Sport 18, no. 4 (2001), 53-87; and John Goulstone, 'The Working Class Origins of Modern Football', The International Journal of the History of Sport 17, no. 1 (2000), 135-43.

${ }^{8}$ For historiography see the following recent papers: Tony Collins, 'Early Football'; Gavin Kitching, 'The Origins'; Curry and Dunning, 'Origins'.

${ }^{9}$ Examples include Swain, 'Early Football'; Peter Swain and Robert Lewis, ' Manchester and the Emergence of an Association Football Culture: an Alternative Viewpoint', The International Journal of the History of Sport 32, no. 9 (2015), 1160-1180; Lewis, 
'Innovation'; Swain, 'Cultural Continuity'; Adrian Harvey, 'Curate's Egg Pursued'; and Adrian Harvey, 'The Curate's Egg Put Back'.

${ }^{10}$ Tony Mason, 'Writing The History of Sport', unpublished seminar paper, Centre for the Study of Social History, University of Warwick, 10 October 1991, quoted in Jeffrey Hill, 'British Sports History: A Post-Modern Future?', Journal of Sport History 23, no.1 (1996), 2. ${ }^{11}$ Fernand Braudel, "Histoire et Science Sociale: La Longue Durée" Annales 13, no.4 (1958), $725-753$.

${ }^{12}$ Immanuel Wallerstein, Unthinking Social Science (Philadelphia: Temple University Press, 2001), 136.

${ }^{13}$ Dale Tomich, 'The Order of Historical Time: The Longue durée and Micro-History', The

Longue durée and World-Systems Analysis, (Binghamton: Binghampton University, 2008), 2.

${ }^{14}$ William H McNeill, 'Fernand Braudel, Historian', The Journal of Modern History, 73, no.1 (2001), 133.

${ }^{15}$ Jo Guldi and David Armitage, The History Manifesto (Cambridge: Cambridge University Press, 2014), 63.

${ }^{16}$ Owen Hufton, 'Fernand Braudel', Past \& Present, 112 (1986), 112.

${ }^{17}$ Fernand Braudel, The Mediterranean and the Mediterranean World in the Age of Philip II (London: Harper and Row, 1972)

${ }^{18}$ Ulysses Santamaria and Anne M Bailey, 'A Note on Braudel's Structure as Duration', History and Theory, 23, no. 1 (1984), 82.

${ }^{19}$ Fernand Braudel, On History (Chicago: University of Chicago Press, 1982), 75.

${ }^{20}$ Santamaria and Bailey, 'A Note', 81.

${ }^{21}$ Peter Stanfield, "'Pix Biz Spurts with War Fever": Film and the Public Sphere - Cycles and Topicality', Film History: An International Journal, 25, no. 1-2 (2013): 222.

22 Santamaria and Bailey, 'A Note', 81.

${ }^{23}$ Ibid.

${ }^{24}$ Michael Ermarth, 'On History. By Fernand Braudel', The Business History Review, 56, no. 1 (1982): 90 .

${ }^{25}$ Immanuel Wallerstein, Unthinking, 137.

${ }^{26}$ William Thomas Dixon, History of Turton Football Club and Souvenir of Carnival and Sports (Bolton: Unknown publisher, 1909), 5.

${ }^{27}$ C.E. Sutcliffe and F. Hargreaves, The History of the Lancashire Football Association (Blackburn: Geo. Toulmin and Sons, 1928), 32.

${ }^{28}$ Fernand Braudel, The Mediterranean, Vol II, 901. 
${ }^{29}$ Fernand Braudel, 'History and the Social Sciences: the Longue durée', in Lee, Richard E., The Longue durée and World Systems Analysis (Albany: State University of New York, 2012), 241-276.

${ }^{30}$ Fernand Braudel, On History, 30-31.

${ }^{31}$ James and Day, 'The Emergence'.

${ }^{32}$ Guldi and Armitage, History Manifesto, 71.

${ }^{33}$ Richard Aldrich, 'The Three Duties of the Historian of Education', History of Education: Journal of the History of Education Society, 32, no. 2 (2010), 136.

${ }^{34}$ Jan Vansina, 'For Oral Tradition (But Not against Braudel)', History in Africa, no. 5 (1978), 351-352.

${ }^{35}$ Geoffrey M. Hodgson, 'Darwin, Veblen and the problem of Causality in Economics', History and Philosophy of the Life Sciences 23 (2001), 385-423.

${ }^{36}$ Guldi and Armitage, History Manifesto, 29; Aldrich, 'Three Duties', 135.

${ }^{37}$ Guldi and Armitage, History Manifesto, 115.

${ }^{38}$ Santamaria and Bailey, 'A Note', 82.

${ }^{39}$ Richard A Gould, 'Ethnoarchaeology and the Past: Our Search for the "Real Thing", Fennoscandia archaeologica, VI (1989), 7.

40 James and Day, 'The Emergence', 56-59; James, 'Manchester's Footballing Pioneers'.

${ }^{41}$ Swain and Lewis, 'Manchester'.

42 James, 'Manchester's Footballing Pioneers', 1149-1155.

${ }^{43}$ Arthur P Molella, 'The Longue durée of Abbott Payson Usher: A. P. Usher, A history of Mechanical Inventions', Technology and Culture, 46, no.4 (2005), 796.

${ }^{44}$ Guldi and Armitage, History Manifesto, 29.

${ }^{45}$ Martin Johnes and Bob Nicholson, 'Sport History and Digital Archives in Practice', in Gary Osmond and Murray G Phillips, Sport History in the Digital Era (Urbana: University of Illinois Press, 2015), 53-55.

${ }^{46}$ A limited run of the Athletic News was added to the British Newspaper Archive's digital collection in the early months of 2016 , but there are significant gaps, while the International Sport \& Leisure History group at Manchester Metropolitan University established a project in 2015 to digitize three leading sports newspapers produced in Manchester.

47 'Miscellaneous', Manchester Times, 26 December 1840, 2.

${ }^{48}$ Ignacio Olabarri, “ New' New History: A Longue durée Structure”, History and Theory, 34, no.1 (1995): 7. 
${ }^{49}$ Yuan Bi, 'Integration or Resistance: the Influx of Foreign Capital in British Football in the Transnational Age', Soccer \& Society, 16, no.1 (2015), 17-41.

50 'Four New Clubs Elected', Yorkshire Post, 11 March 1919.

${ }^{51}$ Matthew Taylor, The Leaguers: The Making of Professional Football in England, 19001939 (Liverpool: Liverpool University Press, 2005), 15-17.

52 'Four New Clubs Elected', Yorkshire Post, 11 March 1919.

${ }^{53}$ Bell's Life, 20 December 1846, 7.

${ }^{54}$ John Goulstone, Football's Secret History (Upminster 3-2 Books, 2001); Adrian Harvey, Football: The First Hundred Years The Untold Story (Abingdon: Routledge, 2005), 76;

Curry and Dunning, Association Football, 158-159.

55 James and Day, 'The Emergence', 54-56.

${ }^{56}$ Immanuel Wallerstein et al, 'Discussion', Review, 1 (1978): 98.

${ }^{57}$ Stanley Bober, The Economics of Cycles and Growth (New York: John Wiley \& Sons, 1968), 44-45

${ }^{58}$ Guldi and Armitage, History Manifesto, 133.

${ }^{59}$ In addition to the four documented within the main text, the other seven broad Transformational periods are Dominance of League Football; Mass Spectator Sport; England's Isolation; World Cup \& European Success; Disasters, Demonstrations and Hooliganism; Premier League Birth; and Overseas Ownership/Globalisation of the English Game.

${ }^{60}$ Gary James, The Emergence of Footballing Cultures: Manchester 1840-1919 (Manchester: Manchester University Press, to be published 2017).

${ }^{61}$ Ignacio Olabarri, “New’ New History”, 1.

${ }^{62}$ Guldi and Armitage, History Manifesto, 119.

${ }^{63}$ Bober, The Economics, 44.

${ }^{64}$ Gould, 'Ethnoarchaeology', 7.

${ }^{65}$ Bober, The Economics, 44-45.

${ }^{66}$ Guldi and Armitage, History Manifesto, 38-60.

${ }^{67}$ Ibid., 63.

${ }^{68}$ David Cannadine, 'British History: Past, Present - And Future?', Past and Present, no. 116 (1987), 176-177. Altmetrics and read figures can be read on the Taylor and Francis website, tandfonline.com, for all their journal articles.

${ }^{69}$ Matthew L. McDowell, 'The Field of Play: Phases and Themes in the Historiography of Pre-1914 Scottish Football', The International Journal of the History of Sport, 31 no. 17 
(2014), 2121-40. Students at the University of Maryland, most notably Sam Clevenger, have also been considering applying longue durée principles in their research. See https://thecorpus.wordpress.com/2015/07/17/report-the-history-manifesto-april-20th2015/\#more-725 (Accessed 8 June 2016).

${ }^{70}$ Gould, 'Ethnoarchaeology', 20.

${ }^{71}$ Martin Johnes, 'What's the Point of Sports History?', The International Journal of the History of Sport, 30, no.1 (1995): 102-8.

${ }^{72}$ Ross McKibbin, 'Sports History: Status, Definitions and Meanings', Sport in History, 31, no.2 (2011): 167-174.

${ }^{73}$ Guldi and Armitage, History Manifesto, 117

${ }^{74}$ Vamplew, 'Sporting a Handicap'.

${ }^{75}$ David Armitage, 'What's the Big Idea? Intellectual History and the Longue durée', History of European Ideas, 38, no. 4 (2012): 493-507.

${ }^{76}$ Andrew Sherratt, 'Reviving the Grand Narrative: Archaeology and Long-term Change. The Second David L Clarke Memorial Lecture', Journal of European Archaeology, 3, no.1 (2013), 5 .

${ }^{77}$ Matthew L. McDowell, 'Field of Play', 2134. 